\title{
Náuseas no Natal: o papel do médico de família no diagnóstico de doença grave
}

Rebeca Martins Natal,* Inês Andrade Rosa*

\section{RESUMO}

Introdução: O médico de família (MF) é com frequência o primeiro contacto do utente com os cuidados de saúde, lidando com a doença numa fase precoce e cujos sintomas são ainda inespecíficos. Com este caso pretende-se promover a reflexão sobre o papel do MF nas várias etapas do processo diagnóstico, bem como as características da medicina geral e familiar e dos cuidados de saúde primários que o facilitam.

Descrição do caso: Mulher de 48 anos, pertencente a uma família reconstruída e índice socioeconómico III de Graffar. Tem antecedentes pessoais de síndroma depressivo (medicada com fluoxetina), encontrando-se em climatério. Recorreu à consulta por náuseas e enfartamento com dez dias de evolução, episódio de vómito isolado na véspera de Natal e prurido generalizado. Objetivamente apresentava dor discreta à palpação epigástrica. Foi medicada sintomaticamente e pediu-se avaliação analítica e ecografia abdominal. Regressou três dias depois por icterícia das escleróticas e acolia, mantendo náuseas. Negava colúria ou febre. Os exames complementares de diagnóstico vieram a revelar analiticamente uma hiperbilirrubinemia conjugada; ecograficamente apresentava marcada dilatação da via biliar principal, imagem nodular no corpo/cauda pancreáticos e múltiplos conglomerados adenopáticos adjacentes aos grandes vasos. Não apresentava sintomas consumptivos evidentes. Pediu-se tomografia computorizada abdominal que revelou conglomerado adenopático envolvendo a cabeça do pâncreas, traduzindo provável doença linfoproliferativa. Foi referenciada com caráter urgente à consulta de hemato-oncologia onde se confirmou o diagnóstico: linfoma não-Hodgkin B difuso de grandes células. Cumpriu oito ciclos de quimioterapia e atualmente encontra-se em remissão. Comentário: Apesar de a tomada de decisão do MF dever basear-se no padrão de morbilidade da comunidade e no contexto sociocultural do doente, não deve ser desvalorizada a diversidade de hipóteses de diagnóstico que poderão resultar da evolução natural da doença. O MF deve suportar-se das vantagens da continuidade e da acessibilidade aos cuidados para este processo, potenciando assim o seu papel diagnóstico.

Palavras-chave: Médico de família; Cuidados de saúde primários; Linfoma.

\section{INTRODUÇÃO}

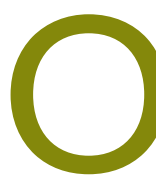

médico de família (MF) é muitas vezes o primeiro contacto do utente com os cuidados de saúde e, por esse motivo, lida com a doença numa fase inicial e ainda inespecífica.

Por ser frequentemente confrontado com sintomas indiferenciados, o MF deve suportar-se na prevalência e incidência da doença na comunidade para a tomada de decisão, nunca desvalorizando, contudo, a pluralidade de hipóteses diagnósticas que destes sintomas podem advir com a evolução da história natural do doente.

*USF Cova da Piedade
Por outro lado, o MF dispõe de uma posição privilegiada neste processo de investigação diagnóstica. Em medicina geral e familiar (MGF) existe uma continuidade na prestação de cuidados que permite ao MF um maior conhecimento do contexto sociocultural e das características individuais de cada doente. Esta continuidade de cuidados promove o estabelecimento de uma relação médico-paciente única, que é também ela própria facilitadora do processo diagnóstico. ${ }^{1}$ Sob outra perspetiva, em cuidados de saúde primários (CSP) pressupõe-se a existência de uma maior acessibilidade aos cuidados de saúde ${ }^{2}$ que é extensível ao MF e que lhe permite também adaptar o acompanhamento às necessidades dos seus utentes. O MF pode e deve usufruir 
de todas estas vantagens quando confrontado com apresentações de doença em fase precoce.

O caso clínico que se relata é exemplificativo do processo de tomada de decisão de um MF perante uma forma de apresentação atípica, e inicialmente inespecífica, de uma doença grave e cuja precocidade de deteção influencia substancialmente o prognóstico do doente. Assim, com este caso, pretende-se fazer uma análise crítica e promover a reflexão sobre as particularidades do papel do MF nas várias etapas do processo diagnóstico, bem como das características da MGF e dos CSP que o facilitam.

\section{DESCRIÇÃO DO CASO}

Doente do sexo feminino, com 48 anos e de raça caucasóide. Divorciada, tem dois filhos do primeiro casamento, com 20 e 25 anos. Mora com o atual marido há cerca de quinze anos e com o filho, constituindo uma família reconstruída. A filha de 25 anos encontra-se a viver com o pai desde o divórcio, em 2008, por opção própria, situação que a afastou da mãe nos últimos anos. Trabalha como administrativa num escritório e pertence a uma classe socioeconómica III de Graffar. Tem como problemas de saúde ativos um excesso de peso (índice de massa corporal $27,7 \mathrm{~kg} / \mathrm{m}^{2}$ ) e uma perturbação depressiva, medicada com fluoxetina $20 \mathrm{mg} /$ dia há seis meses. Não apresenta alergias medicamentosas conhecidas. É uma ex-fumadora (carga tabágica de 18 Unidades Maço Ano), sem hábitos etílicos ou toxifílicos. Na história ginecológica/obstétrica salientam-se dois partos distócicos (cesariana); encontra-se em fase de climatério e utiliza o método barreira como contracetivo. Como antecedentes familiares destacam-se a mãe com o diagnóstico de diabetes mellitus tipo 2 e um tio materno com uma neoplasia do cólon aos 68 anos.

Recorreu à consulta aberta no dia 5 de janeiro de 2016, tendo sido observada por uma médica que não a sua MF. Apresentava um quadro de náuseas e enfartamento com dez dias de evolução. Relatava um único episódio de vómito na véspera de Natal e referia ainda prurido generalizado, predominantemente vespertino, com o mesmo tempo de evolução. Automedicou-se com um antiácido de venda livre (carbonato de cálcio, alginato e bicarbonato de sódio), sem qualquer alívio sintomático. Objetivamente não eram observadas alte- rações cutâneas e apenas se destacava uma dor ligeira à palpação profunda na região epigástrica. Foi medicada sintomaticamente com esomeprazol 20mg, domperidona $10 \mathrm{mg}$ e hidroxizina $25 \mathrm{mg}$ e foram pedidas ecografia abdominal e uma avaliação analítica, incluindo bilirrubinas total e direta, transaminases, proteína C-reativa (PCR) e análise sumária da urina. De forma a reavaliar clinicamente a doente e analisar os resultados destes exames agendou-se consulta para a sua MF para 12 de janeiro.

Não obstante, três dias depois, a doente recorreu novamente à consulta aberta por ter acordado nesse dia com os "olhos amarelos" (sic), tendo sido observada por outra médica que não a sua MF. Mantinha náuseas, enfartamento e prurido apesar da terapêutica prescrita, referindo ainda acolia. Negava colúria ou febre. Ao exame objetivo, além de dor, apresentava ainda empastamento à palpação na região epigástrica. A análise sumária de urina, que tinha já sido realizada, não apresentava alterações e efetuou-se ainda um teste rápido de urina que se revelou inocente. A doente havia já realizado os restantes exames pedidos na consulta anterior, mas ainda não estavam disponíveis. Suspeitou-se de um possível quadro de colestase obstrutiva, optou-se por tranquilizar a doente e aguardar os resultados dos exames em curso.

A 12 de janeiro foi observada pela sua MF em consulta programada. Quando efetuada uma história mais detalhada, admitia algum cansaço e apresentava uma perda ponderal de $14 \%$ em oito meses, embora tivesse feito várias dietas na tentativa de emagrecer. Analiticamente verificava-se uma hiperbilirrubinemia conjugada e uma elevação das transaminases hepáticas (Quadro I). Perante o quadro de icterícia de etiologia a esclarecer foi pedido novo estudo analítico, incluindo serologias para vírus da hepatite, e agendada consulta programada para o dia seguinte para avaliação dos resultados dos exames e orientação concordante.

Na reavaliação analítica já não apresentava hiperbilirrubinemia, verificava-se uma elevação da fosfatase alcalina e as transaminases, apesar de elevadas, tinham também diminuído (Quadro I). A ecografia abdominal, por sua vez, evidenciava "marcada dilatação da via biliar principal com calibre de $11 \mathrm{~mm}$ com dilatação das vias biliares intra-hepáticas. Pâncreas globoso, observando-se na zona de transição corpo/cauda imagem 


\begin{tabular}{|c|c|c|c|}
\hline Parâmetro analítico & $\begin{array}{l}\text { Valor de } \\
\text { referência }\end{array}$ & $\begin{array}{c}\text { Resultado } \\
05.01 .2016\end{array}$ & $\begin{array}{c}\text { Resultado } \\
12.01 .2016\end{array}$ \\
\hline Bilirrubina direta (mg/dL) & $<1,2$ & 1,38 & 0,61 \\
\hline Bilirrubina total (mg/dL) & $<0,3$ & 1,72 & 0,84 \\
\hline GGT (U/L) & $<40$ & 211 & - \\
\hline TGO (U/L) & $<32$ & 420 & 172 \\
\hline TGP (U/L) & $<35$ & 860 & 644 \\
\hline PCR (mg/dL) & $<0,2$ & 0,49 & - \\
\hline $\mathrm{FA}(\mathrm{mg} / \mathrm{dL})$ & $35-104$ & - & 231 \\
\hline $\begin{array}{l}\mathrm{Ag} \mathrm{HBs} \\
\mathrm{Ac} \text { anti-HBc} \\
\text { Ac anti-VHA } \\
\text { Ac anti-VHC }\end{array}$ & - & - & Negativos \\
\hline
\end{tabular}

Legenda: Ac (anticorpo); Ag HBs (antigénio de superfície do vírus da hepatite B); FA (fosfatase alcalina); GGT (gama glutamil transpeptidase); $\mathrm{HBC}$ (partícula central nucleocapsídica do vírus da hepatite B); mg/dL (miligrama por decilitro); PCR (proteína C-reativa); TGO (transaminase glutâmico-oxalacética); TGP (transaminase glutâmico-pirúvica); U/L (unidade por litro); VHA (vírus da hepatite A); VHC (vírus da hepatite C).

nodular hipoecogénica com $2 \mathrm{~cm}$ que poderá traduzir formação quística não pura a caracterizar. Múltiplos conglomerados adenopáticos adjacentes aos grandes vasos o maior com $6,5 \mathrm{~cm}$."

Dada a suspeita de carcinoma da cabeça do pâncreas foi requisitada uma tomografia computorizada (TC) abdomino-pélvica com caráter urgente, que foi realizada uma semana depois, tendo revelado "hepatomegalia ligeira, via biliar principal ectasiada e redução abrupta do calibre na região pancreática, com múltiplos conglomerados de adenopatias retroperitoneais, mesentéricas e pélvicas, as maiores com $8,5 \mathrm{~cm}$, que traduzem provável doença linfoproliferativa".

A má notícia foi-lhe transmitida pela sua MF na consulta seguinte e a doente foi referenciada à consulta de hemato-oncologia do hospital de referência com caráter urgente, tendo sido observada a 21 de janeiro.

Os exames complementares realizados em contexto hospitalar confirmaram o diagnóstico de linfoma não-Hodgkin B difuso de grandes células em estadio III A. Iniciou quimioterapia, tendo completado oito ciclos. Atualmente mantém-se em remissão.

\section{COMENTÁRIO}

Este caso levanta inúmeras questões acerca do processo diagnóstico conduzido por um MF, nomeadamente em relação à precocidade da apresentação da doença com a qual é frequentemente confrontado; à tomada de decisão de acordo com a incidência e prevalência das doenças na comunidade e contexto em que exerce; à continuidade de acompanhamento, ao conhecimento das particularidades de cada pessoa que acompanha e da relação que estabelecem; e à acessibilidade aos cuidados permitida pelo exercício da profissão em CSP.

Um quadro de náuseas, enfartamento e apenas um episódio de vómito alimentar numa época festiva culturalmente caracterizada por excessos alimentares sugere uma dispepsia funcional ou uma gastroenterite, situações frequentes na consulta de MGF. Sabe-se que aproximadamente um em cada quatro pacientes que apresenta sintomas dispépticos consulta o seu MF e, destes, a maioria tem uma dispepsia funcional. ${ }^{3}$

No entanto, a presença de prurido generalizado torna este quadro aparentemente comum numa situação atípica, obrigando à consideração de outros diagnósticos diferenciais. Nesta utente, a presença de uma perturbação psiquiátrica medicada pode constituir um fator confundidor e induzir a atribuição do prurido a causa psicogénica ou secundária ao tratamento antidepressivo. ${ }^{4}$ Contudo, os sintomas e sinais que se desenvolveram progressivamente foram orientando a investigação etiológica, validando a utilidade do tempo enquanto ferramenta diagnóstica, já descrita por McWhinney ${ }^{5}$ no contexto da prática da MGF. O aparecimento de icterícia e acolia sugeriram um quadro de colestase que acabou por se comprovar analiticamente, ficando de esclarecer a etiologia; do estudo imagiológico confirmou-se a existência de uma colestase obstrutiva de causa extra-hepática, secundária a uma doença linfoproliferativa. O prurido foi, assim, um sintoma-chave para o diagnóstico diferencial, tendo motivado o prosseguimento da investigação etiológica e acautelado uma importante mensagem: o MF deve ter sempre presente a multiplicidade de hipóteses diagnósticas que podem resultar de sintomas comuns e estar atento a sinais ou sintomas que possam constituir 
um alerta em quadros aparentemente banais

A manifestação de prurido antecedendo a icterícia coloca ainda em discussão se esta apresentação terá sido a expressão de uma colestase obstrutiva em fase inicial, um sintoma consequente da doença maligna em progressão ou o resultado de ambos. Embora a verdadeira prevalência do prurido nas doenças malignas seja desconhecida, sabe-se que os tumores sólidos, nomeadamente os linfomas não-Hodgkin, são causa pouco frequente deste sintoma, tornando remota a segunda hipótese acima sugerida. ${ }^{4}$

O linfoma é uma neoplasia das células linfoides que se apresenta como um tumor sólido. De entre os tipos de linfoma, o grupo dos não-Hodgkin representa mais de $50 \%$ dos casos, sendo o subtipo Difuso de grandes células B o mais comum nos adultos, em cerca de um terço. Tem um padrão agressivo e de rápida evolução, mas também muito boa resposta à quimioterapia quando diagnosticado e tratado atempadamente. ${ }^{6} \mathrm{~A}$ apresentação deste tipo de neoplasia depende da sua localização e do efeito de massa sobre as estruturas adjacentes; neste caso com compressão da via biliar principal a condicionar colestase e quadro de icterícia obstrutiva. Esta forma de apresentação é rara no tipo de linfoma descrito, embora já tenha sido relatada na literatura. ${ }^{7-10}$

Neste e noutros casos de neoplasias diagnosticadas nos CSP, a precocidade de deteção é facilitada pela acessibilidade e influencia frequentemente o prognóstico do doente. ${ }^{2,5}$ Neste caso, a utente recebeu atendimento médico sempre que solicitado, agendaram-se consultas com a sua MF de forma relativamente célere e potenciou-se ainda a realização de exames e referenciação hospitalar em caráter urgente. É notória a importância da facilidade de acesso aos cuidados de saúde no caso descrito, o que permitiu ao MF uma vigilância de proximidade e em continuidade.

Como nota final, perante o diagnóstico de uma doença grave, como a do caso descrito, sugere-se ainda que o MF seja também quem se encontra numa posição preferencial para transmitir esta informação ao doente. A forma como uma má notícia é comunicada influencia o ajustamento emocional e prognóstico do doente, fazendo deste um momento da maior relevância. ${ }^{11}$ Enquanto médico que acompanha o doente ao longo do processo de diagnóstico e com o qual man- tém uma relação pré-existente, ninguém melhor que o MF para conhecer as preocupações e manter um diálogo aberto com o doente no momento da transmissão do diagnóstico.

Este caso é um exemplo da apresentação atípica de uma doença grave, cuja clínica inicialmente inespecífica, mas frequente nos CSP, dificilmente aponta para o diagnóstico final. Alerta para o facto de que, apesar da tomada de decisão do MF dever basear-se no padrão de morbilidade da comunidade e no contexto sociocultural do doente, não deve ser desvalorizada a diversidade de hipóteses de diagnóstico que poderão resultar da evolução da história natural da doença. O MF deve suportar-se das vantagens da continuidade e da acessibilidade de cuidados inerentes à MGF e aos CSP para este processo, potenciando assim o seu papel diagnóstico.

\section{REFERÊNCIAS BIBLIOGRÁFICAS}

1. WONCA Europe. A definição europeia de medicina geral e familiar (clínica geral / medicina familiar) [Internet]. WONCA Europe; 2002. Available from: http://www.woncaeurope.org/sites/default/files/documents/European\%20Definition\%20in\%20Portuguese.pdf

2. Atun R. What are the advantages and disadvantages of restructuring a health care system to be more focused on primary care services? [Internet]. Copenhagen:WHO Regional Office for Europe; 2004. Available from: http://www.euro.who.int/_data/assets/pdf_file/0004/74704/ E82997.pdf

3. Jones R, Lydeard S. Prevalence of symptoms of dyspepsia in the community. BMJ. 1989;298(6665):30-2.

4. Millington GW, Collins A, Lovell CR, Leslie TA, Yong AS, Morgan JD, et al. British Association of Dermatologists' guidelines for the investigation and management of generalized pruritus in adults without an underlying dermatosis, 2018. Br J Dermatol. 2018;178(1):34-60.

5. Freeman TR. Manual de medicina de família e comunidade de McWhinney. $3^{\text {a }}$ ed. Porto Alegre: Artmed; 2010.

6. Longo DL. Malignancies of lymphoid cells. In: Kasper DL, Fauci AS, Hauser SL, Longo DL, Jameson JL, Loscalzo J, editors. Harrison's principles of internal medicine. 19th ed. McGraw-Hill; 2015. p. 695-710.

7. Chu KM, Lai EC, Fan ST. Primary lymphoma presenting as intra-abdominal mass and obstructive jaundice. Am J Gastroenterol. 1995;90(3):482-4.

8. Ravindra KV, Stringer MD, Prasad KR, Kinsey SE, Lodge JP. Non-Hodgkin lymphoma presenting with obstructive jaundice. Br J Surg. 2003;90 (7):845-9.

9. Wakabayashi H, Yachida S, SuzukiY. Obstructive jaundice caused by bile duct involvement in intra-abdominal non-Hodgkin lymphoma: an unusual initial manifestation. Dig Liver Dis. 2007;39(7):692.

10. Odemiş B, Parlak E, Başar O, Yüksel O, Sahin B. Biliary tract obstruction secondary to malignant lymphoma: experience at a referral cen- 
ter. Dig Dis Sci. 2007;52(9):2323-32.

11. Baile WF, Buckman R, Lenzi R, Glober G, Beale EA, Kudelka AP. SPIKES: a six-step protocol for delivering bad news: application to the patient with cancer. Oncologist. 2000;5(4):302-11.

\section{CONFLITO DE INTERESSES}

Os autores declaram não ter quaisquer conflitos de interesse.

\author{
ENDEREÇO PARA CORRESPONDÊNCIA \\ Rebeca Martins Natal \\ E-mail: rebecanatal@gmail.com \\ http://orcid.org/0000-0003-4333-4716
}

Recebido em 31-01-2017

Aceite para publicação em 26-04-2018

\section{ABSTRACT}

NAUSEA DURING CHRISTMAS: THE ROLE OF THE FAMILY PHYSICIAN IN THE DIAGNOSIS OF SEVERE ILLNESS Introduction: The family physician (FP) is often the patient's first contact with health system, dealing with diseases in early stages when symptoms are still nonspecific. With this case report, we intend to promote the reflection about the role of FP in the several stages of the process of diagnosis, and about the characteristics intrinsic to general and family medicine specialty that facilitate it.

Case report: We present the case of a 48-years-old female, integrating a reconstructed family of medium socioeconomic status, with history of depressive syndrome (medicated with fluoxetine), in climacteric. She presented with nausea, bloating, and generalized pruritus for the last 10-days and a single vomit on Christmas Eve. The physical examination revealed mild abdominal pain in the epigastrium. She was prescribed according her symptoms and ordered blood tests and an abdominal ultrasound. The patient returned 3 days later with scleral icterus and acholic stools, maintaining nausea. No choluria or fever were present. Complementary diagnostic tests showed conjugated hyperbilirubinemia; ultrasound revealed pronounced dilation of the common bile duct, a nodular image in the pancreatic body/tail and multiple adenopatic conglomerates. The patient had no evident consumptive symptoms. Abdominal computed tomography revealed an adenopatic conglomerate implicating the pancreatic head, most likely to be associated with a lymphoproliferative disorder. Patient was urgently referred to the Hematology-Oncology consultation where the final diagnosis was established: non- Hodgkin's diffuse large B cell lymphoma. She completed 8 sessions of chemotherapy and is currently under remission.

Comment: Although the FP's decision-making process is mainly based on the community epidemiology of diseases and patient's sociocultural context, the diversity of diagnostic hypothesis that may result from the natural course of disease can't be forgotten nor underestimated. The FP should rely on the advantages of health care continuity and accessibility, thus enhancing his diagnostic role.

Keywords: Family physician; Primary health care; Lymphoma. 